\title{
High Glucose-Induced Reactive Oxygen Species Stimulates Human Mesenchymal Stem Cell Migration Through Snail and EZH2-Dependent E-Cadherin Repression
}

\author{
Ji Young Oha, Gee Euhn Choi ${ }^{\mathrm{b}}$ Hyun Jik Lee ${ }^{\mathrm{b}}$ Young Hyun Jung ${ }^{\mathrm{b}}$ So Hee Ko ${ }^{\mathrm{b}}$ \\ Chang Woo Chae ${ }^{b}$ Jun Sung Kim ${ }^{b}$ Seo Yihl Kim ${ }^{b}$ Jae Ryong Limb \\ Chang-Kyu Lee ${ }^{a, c}$ Ho Jae Han ${ }^{b}$
}

aDepartment of Agricultural Biotechnology, Animal Biotechnology Major, and Research Institute of Agriculture and Life Science, Seoul National University, Seoul, 'bepartment of Veterinary Physiology, College of Veterinary Medicine, Research Institute for Veterinary Science, and BK21 PLUS Program for Creative Veterinary Science Research, Seoul National University, Seoul, Institute of Green Bio Science and Technology, Seoul National University, Pyeong Chang, Kangwon do, Korea

\section{Key Words}

High glucose $\cdot$ E-cadherin $•$ Umbilical cord blood derived mesenchymal stem cells $\cdot$ Migration - Wound healing

\begin{abstract}
Background/Aims: Glucose plays an important role in stem cell fate determination and behaviors. However, it is still not known how glucose contributes to the precise molecular mechanisms responsible for stem cell migration. Thus, we investigate the effect of glucose on the regulation of the human umbilical cord blood-derived mesenchymal stem cell (hUCB-MSC) migration, and analyze the mechanism accompanied by this effect. Methods: Western blot analysis, wound healing migration assays, immunoprecipitation, and chromatin immunoprecipitation assay were performed to investigate the effect of high glucose on hUCB-MSC migration. Additionally, hUCB-MSC transplantation was performed in the mouse excisional wound splinting model. Results: High concentration glucose $(25 \mathrm{mM})$ elicits hUCB-MSC migration compared to normal glucose and high glucose-pretreated hUCB-MSC transplantation into the wound sites in mice also accelerates skin wound repair. We therefore elucidated the detailed mechanisms how high glucose induces hUCB-MSC migration. We showed that high glucose regulates E-cadherin repression through increased Snail and EZH2 expressions. And, we found high glucose-induced reactive oxygen species (ROS) promotes two signaling; JNK which regulates $\gamma$-secretase leading to the cleavage of Notch proteins and PI3K/Akt signaling which enhances GSK-3 $\beta$ phosphorylation. High glucose-mediated JNK/ Notch pathway regulates the expression of EZH2, and PI3K/Akt/GSK-3 $\beta$ pathway stimulates Snail stabilization, respectively. High glucose enhances the formation of EZH2/Snail/HDAC1
\end{abstract}

Ho Jae Han

KARGER
Department of Veterinary Physiology, College of Veterinary Medicine, Research Institute for Veterinary Science, 85-902, 1, Gwanak-ro, Gwanak-gu, Seoul (Republic of Korea) Tel. +82-2-880-1261, Fax +82-2-885-2732, E-Mail hjhan@snu.ac.kr 
Oh et al.: High Glucose Mediates hUCB-MSC Migration

complex in the nucleus, which in turn causes E-cadherin repression. Conclusion: This study reveals that high glucose-induced ROS stimulates the migration of hUCB-MSC through E-cadherin repression via Snail and EZH2 signaling pathways.

\section{Introduction}

Glucose is an essential nutrient resource for cellular bio-energetics and components synthesis, such as protein and lipid [1]. Furthermore, glucose is an important regulatory element that controls cell fate determination in both physiological and pathological conditions [2]. Glucose metabolism plays a key role in proliferation, self-renewal ability, and senescence of stem cells [3]. Previous reports investigating the effects of high glucose on stem cell functions are controversial as there are differing perspectives. For example, some studies have shown that high glucose induces senescence and apoptosis in stem cells [1, $4,5]$. Conversely, other studies have shown that high glucose stimulates proliferation and enhances osteogenic differentiation potential in mesenchymal stem cells (MSCs) [6]. These diverse responses to the high glucose condition may be relevant for the different glucose tolerance of stem cells $[7,8]$. Therefore, further investigation into the underlying mechanism of high glucose on stem cell functions is needed to develop a therapeutic strategy for stem cell therapy.

The migratory ability of stem cell to injury site is a critical factor in determining the therapeutic effect of stem-based therapy. Previous reports suggested that enhancing stem cell migration is a potential strategy for improving the efficacy of tissue regeneration [913]. Moreover, there have been previous studies showing the stimulatory effect of glucose on migration in the various types of cells [14-16]. However, the effect of glucose on stem cell migration is not fully determined. Therefore, identification of a key factor regulating migratory mechanism of stem cells under high glucose conditions is required to improve therapeutic efficacy of stem cell transplantation. Disrupting the cell-cell interaction has been considered an essential step for cell migration. Additionally, cell detachment is regulated by reducing cell adhesion molecules $[17,18]$. Many studies have highlighted that detachment is significant during cell migration by which adhesions disassemble [1921]. Epithelial cadherin (E-cadherin) is a major component of the cell adhesion molecules that are formed at cell-cell adherens junctions to bind cells via a homophilic mechanism [22]. During dissolution of adherens junctions by the reduced E-cadherin expression level, E-cadherin can no longer interact with $\beta$-catenin, which results in increased cell motility [23]. E-cadherin expression can influence various processes that occur during development, organogenesis, tissue formation, and tumor progression [24-26]. In particular, E-cadherin expression has emerged as an important regulator in cellular movement and invasion [27-29]. Furthermore, E-cadherin reduction and delocalization accelerated cell migration through the Notch signaling which controls the disassembly of cell-cell adherens junction [30]. However, the effect of high glucose on the disruption of E-cadherin-dependent cell-cell adherens junction in enhancing cell migration is still unknown.

MSCs are multipotent stem cells, which have differentiation potentials for various kinds of somatic cells, such as osteoblasts, adipocytes, chondrocytes, myoblasts, and neural cells $[31,32]$. Due to various limitations in embryonic stem cells (ESCs) and induced pluripotent stem cells (iPSCs) research in teratoma formation as well as political and ethical restrictions, human umbilical cord blood-derived mesenchymal stem cells (hUCB-MSCs) are considered promising stem cell resources for stem cell-based therapies. In addition, our previous studies demonstrated that the transplantation of hUCB-MSCs accelerates the wound healing process by promoting their migratory activity $[33,34]$. Thus, we investigated the molecular mechanisms underlying the effect of high glucose on hUCB-MSC migration and the wound healing effect of high glucose-pretreated hUCB-MSC transplantation in the mouse skin wound model. 


\section{Cellular Physiology Cell Physiol Biochem 2018;46:1749-1767 \begin{tabular}{l|l} 
and Biochemistry Publisher 10.1159/000489360 & $\begin{array}{l}\text { (c) } 2018 \text { The Author(s). Published by S. Karger AG, Basel } \\
\text { www.karger.com/cpb }\end{array}$
\end{tabular}}

Oh et al.: High Glucose Mediates hUCB-MSC Migration

\section{Materials and Methods}

\section{Materials}

Human UCB-MSCs were kindly provided from the MEDIPOST Co., Ltd. (Seoul, Korea) which were isolated and expanded according to previous report [35]. Fetal bovine serum (FBS) was purchased from BioWhittaker Inc. (Walkersville, MO, USA). Antibodies specific for phospho (p)-JNK (cat\# sc-6254), JNK (cat\# sc-7345), p-Erk (cat\# sc-7383), Erk (cat\# sc-94), p38 (cat\# sc-7149), p-GSK-3ß (cat\# sc-11757), GSK-3 $\beta$ (cat\# sc-9168), Snail (cat\# sc-28199), EZH2 (cat\# sc-25383), E-Cadherin (cat\# sc-7870), $\beta$-actin (cat\# sc-47778), and Lamin A/C (cat\# sc-20681) were purchased from Santa Cruz Biotechnology, Inc. (Santa Cruz, CA, USA). Anti-cleaved Notch1 (cat\# 4147), Suz12 (cat\# 3737), Akt (cat\# 9272), p-p38 (cat\# 9211), p-Akt ${ }^{\mathrm{Th} 308}$ (cat\# 13038) and p-Akt ${ }^{\mathrm{Ser} 473}$ (cat\# 4060) antibodies were purchased from Cell Signaling Technology, Inc. (Danvers, MA, USA). Antibody specific for EED (cat\# 09-774) was purchased from Millipore (Billerica, MA, USA). Secondary antibodies (anti-rabbit; cat\# sc-2004, anti-mouse; cat\# sc-2005, anti-goat; cat\# sc-2768) were obtained from Santa Cruz Biotechnology, Inc. (Santa Cruz, CA, USA). D-, L-Glucose, N-Acetyl-L-cystein (NAC), L-685, 458, LY294002, and lithium chloride (LiCl) were obtained from Sigma Chemical Company (St. Louis, MO, USA). Human Nuclear Antigen (HNA; Alexa Fluor 488 antibody) was purchased from Novus Biologicals (Littleton, CO, USA). 5-(and-6)-carboxy-2', 7'-dichlorofluorescein diacetate (DCF-DA) was purchased from Molecular Probes (Eugene, OR, USA). Akt specific inhibitor was purchased from CalBiochem (La Jolla, CA, USA).

\section{hUCB-MSC culture}

hUCB-MSCs were cultured according to previous report [36]. In this study, passage of hUCB-MSCs from five to eight was used and there is no discernible difference between passages [37]. hUCB-MSCs without feeder layer were cultured in the alpha-modified minimum essential medium ( $\alpha$-MEM; Thermo, MA, USA) supplemented with $0.1 \mathrm{mM} \beta$-mercaptoethanol, $1 \%$ penicillin and streptomycin, and $10 \%$ FBS. Cells were grown on gelatinized $100-\mathrm{mm}$ diameter culture dishes at $37^{\circ} \mathrm{C}$ with $5 \% \mathrm{CO}_{2}$ in the incubator. Cells were transferred to fresh serum-containing $\alpha$-MEM at least once every two days. Cells, cultured at $70-80 \%$ confluence, were washed twice with phosphate-buffered saline (PBS), and were transferred to serum-free $\alpha$-MEM prior to experiments.

\section{AD-MSC culture}

AD-MSCs without feeder layer were cultured in the $\alpha$-MEM (Thermo, MA, USA) supplemented with $0.1 \mathrm{mM} \beta$-mercaptoethanol, $1 \%$ penicillin and streptomycin, and 10\% FBS. Cells were grown on gelatinized 100 -mm diameter culture dishes at $37^{\circ} \mathrm{C}$ with $5 \% \mathrm{CO}_{2}$ in the incubator. Cells were transferred to fresh serumcontaining $\alpha$-MEM at least once every two days. Cells were washed twice with PBS, and were transferred to serum-free $\alpha$-MEM prior to experiments.

\section{Mouse excisional wound splinting model}

Mouse excisional wound splinting model and hUCB-MSC transplantation were performed, as described in the previous reports [38]. Male ICR mice aged 8 weeks were purchased from Han Lim Experimental Animal (Suwon, Korea). Mice were acclimated and stabilized in new surroundings for 4 days prior to the start of research and collecting data. To investigate the functional effects of high glucose-pretreated hUCBMSC, mice were randomly divided into four groups ( $n=6$ each group): Vehicle, high glucose, hUCB-MSCs, and high glucose-pretreated hUCB-MSCs. To investigate the role of Snail and EZH2 in the migration of hUCBMSC toward wound site, mice were randomly divided into six groups ( $\mathrm{n}=6$ each group): non-targeting $(N T)$ siRNA + hUCB-MSC, NT siRNA + high glucose-pretreated hUCB-MSC, Snail siRNA + hUCB-MSC, Snail siRNA + high glucose-pretreated hUCB-MSC, EZH2 siRNA + hUCB-MSC, and EZH2 siRNA + high glucosepretreated hUCB-MSC. Cells were transfected with either Snail or EZH2 siRNA for $24 \mathrm{~h}$ prior to the high glucose treatment for $24 \mathrm{~h}$. Mice were anesthetized with $3 \%$ isoflurane in a mixture of $\mathrm{N}_{2} \mathrm{O} / \mathrm{O}_{2}$ gas. Wounds were created by a $6 \mathrm{~mm}$ diameter biopsy punch (Kai Medical, Seki, Japan) on the back of a mouse, and a silicone splinting ring was attached around the wound using medical adhesive with several stitches. $1 \times 10^{6}$ hUCB-MSCs in $100 \mu \mathrm{L}$ saline were transplanted into the dermis at four sites around the wounds. Wound dressings were applied using Tegaderm ${ }^{\mathrm{TM}}(3 \mathrm{M}$, St. Paul, MN, USA) to keep out water, dirt and germs. Mice were placed in individual cages in controlled rooms $\left(24 \pm 2{ }^{\circ} \mathrm{C}, 12 / 12 \mathrm{~h}\right.$ light/dark cycle with lights on at 7 
Oh et al.: High Glucose Mediates hUCB-MSC Migration

AM). All wounds were monitored and photographed at different times (days $0,3,6$, 9, and 11) by using a digital camera system (Canon, Tokyo, Japan). Percentages of wound size were calculated and analyzed by using Image J program. Mice were euthanized for the collection of wound tissue samples at day 11 . The samples were fixed with $4 \%$ paraformaldehyde (PFA) in PBS for $4 \mathrm{~h}$. Subsequently, for dehydration, the samples were incubated in $20 \%$ sucrose in PBS at room temperature for $2 \mathrm{~h}$, and then were incubated in $30 \%$ sucrose at $4{ }^{\circ} \mathrm{C}$ overnight. The next day, the tissues were embedded in O.C.T. compound (Sakura Finetek, Torrance, CA, USA) and were frozen immediately at $-70^{\circ} \mathrm{C}$.

\section{Haematoxylin and Eosin (H\&E) staining}

Wound tissues were cut at thickness of $6 \mu \mathrm{m}$ using a cryostat (Leica Biosystems, Nussloch, Germany) and mounted on SuperFrost Plus slides (Thermo Fisher Scientific, Waltham, MA, USA). The frozen tissue sections were fixed with $4 \%$ PFA for 5 min and were washed with running tap water for $5 \mathrm{~min}$. Next, the tissues were stained with haematoxylin for $3 \mathrm{~min}$ and washed with running tap water for $5 \mathrm{~min}$. The slides were placed in acid alcohol solution (1\% $\mathrm{HCl}$ in $70 \%$ alcohol) and were stained with eosin solution for $30 \mathrm{sec}$. The slides were repeatedly dehydrated with $95 \%$ and $100 \%$ alcohol 3 times, each for $3 \mathrm{sec}$. Next, the slides were placed in xylene for $3 \mathrm{sec}$, and then were mounted on clear glass slides. The slides were photographed using Eclipse Ts2-FL microscope (Nikon Corporation, Tokyo, Japan).

\section{Intracellular ROS detection}

Intracellular ROS detection was described in previous reports [39]. ROS was detected by using DCF$\mathrm{DA}$, which is a fluorescence-based probe for ROS detection. Cells were treated with $10 \mu \mathrm{M}$ DCF-DA and were wrapped it in foil, due to light sensitivity, then placed on shaking incubator for $30 \mathrm{~min}$ at room temperature. Cells were observed using FluoView ${ }^{\mathrm{TM}} 300$ confocal microscope (Olympus, Tokyo, Japan). To measure the intracellular hydrogen peroxide $\left(\mathrm{H}_{2} \mathrm{O}_{2}\right)$ levels, the cells were treated with DCF-DA and were washed using ice-cold PBS twice. The cells were measured by using a luminometer (Victor3; PERKin-Elmer, Waltham, MA).

\section{Oris $^{T M}$ cell migration assay}

hUCB-MSCs were placed at a density of $10^{4}$ cells $/ 0.1 \mathrm{~mL}$ into a $\alpha$-MEM containing serum in Oris $^{\mathrm{TM}}$ cell seeding stoppers (Platypus Technologies, WI, USA), and were incubated until the cells had achieved $90 \%$ confluence of monolayers around the cell exclusion zone [36]. The cells were transferred to serumfree $\alpha$-MEM prior to experiments, and then silicone stoppers were carefully removed after $24 \mathrm{~h}$. The cells were incubated in both with and without high glucose and each signal pathway-related molecule inhibitors/ siRNAs, followed by fixation and staining with $5 \mu \mathrm{M}$ calcein AM (Wako, Osaka, Japan) in dark for $30 \mathrm{~min}$. Fluorescence was measured using a luminometer (Victor3; PERKinElmer Inc., Waltham, MA, USA) and a fluorescent plate reader with excitation and emission wavelengths at $485 \mathrm{~nm}$ and $535 \mathrm{~nm}$, respectively. The measurements were shown as Relative Fluorescence Units (RFU).

\section{Wound-healing migration assay}

hUCB-MSCs were seeded at density of $10^{4}$ cells $/ 0.1 \mathrm{~mL}$ in $35 \mathrm{~mm}$ diameter plates (IBIDI ${ }^{\mathrm{Tm}}$, Martinsried, Germany) in a medium containing serum, and were incubated until the cells had achieved $90 \%$ confluence of monolayers into the inner well of the $\mu$-Dish at $37^{\circ} \mathrm{C}$ and $5 \% \mathrm{CO}_{2}$ as usual [36]. The old medium was aspirated carefully and fresh media was replaced every 2 days. The silicone inserts were carefully removed with sterilized forceps after serum-free treatment for $24 \mathrm{~h}$. The cells were incubated with and without high glucose and indicated agents. Cells were pictured by either an Olympus FluoView ${ }^{\mathrm{TM}} 300$ confocal microscope (Olympus, Tokyo, Japan) or Eclipse Ts2-FL microscope (Nikon Corporation, Tokyo, Japan).

\section{Transfection of small interfering RNA (siRNA)}

hUCB-MSCs that reached $80 \%$ confluence were transfected for $24 \mathrm{~h}$ with either a siRNA specific for Snail1, EZH2 or a NT siRNA as a negative control (25 nM; Dharmacon, Lafayette, CO, USA) using DharmaFECT transfection reagent according to the manufacturer's instructions. The sequences of the siRNAs used in this experiment were as follows: Snail1 5'-GCGAGCUGCAGGACUCUAA-3'. 5'-AAUCGGAAGCCUAACUACA-3', 5'-GUGACUAACUAUGCAAUAA-3' and 5'- GAGUAAUGGCUGUCACUUG-3'; EZH2 5'-GAGGACGGCUUCCCAAUAA-3', 5'- GCUGAAGCCUCAAUGUUUA-3', 5'-UAACGGUGAUCACAGGAUA-3' 
Oh et al.: High Glucose Mediates hUCB-MSC Migration

and 5'- GCAAAUUCUCGGUGUCAAA-3'; Non-targeting 5'-UUCUCCGAACGUGUCACGUTT-3' and 5'ACGUGACACGUUCGGAGAATT-3'. The culture medium was replaced with transfection mixture- and serumfree medium after $6 \mathrm{~h}$ of incubation at $37^{\circ} \mathrm{C}$ and the cells were incubated for $24 \mathrm{~h}$.

\section{Co-Immunoprecipitation (Co-IP)}

hUCB-MSCs were lysed with the co-IP buffer (50 mM Tris- $\mathrm{HCl}$ [pH 7.4] containing $150 \mathrm{mM} \mathrm{NaCl}$, $5 \mathrm{mM}$ EDTA, $2 \mathrm{mM} \mathrm{Na} \mathrm{VO}_{4}, 2.5 \mathrm{mM} \mathrm{Na}_{4} \mathrm{PO}_{7}, 100 \mathrm{mM} \mathrm{NaF}, 200 \mathrm{nM}$ microcystin lysine-arginine and protease inhibitors) according to the previous report [34]. Cell lysates were added with anti-Snail or EZH2 antibodies and Protein A/G PLUS-agarose IP reagent (Pierce; Rockford, IL, USA), and then the cell lysates were incubated for $4 \mathrm{~h}$ in a shaking incubator maintained at $4^{\circ} \mathrm{C}$. The beads were washed more than three times with the coIP buffer, and then the bound proteins with beads were eluted by boiling for $5 \mathrm{~min}$. Samples were analyzed by western blotting with anti-EZH2, EED, Suz12, Snail and histone deacetylase 1 (HDAC1) antibodies.

\section{Cytosol and nuclear fractionation}

hUCB-MSCs were lysed in lysis buffer (20 mM Tris-HCl, 10 mM EGTA, 2 mM EDTA, 2 mM Dithiothreitol, 1\% Triton X-100, $1 \mathrm{mM}$ phenylmethylsulfonylfluoride [PMSF], $25 \mathrm{mg} / \mathrm{mL}$ aprotinin and $10 \mathrm{mg} / \mathrm{mL}$ leupeptin) [34]. Lysates were homogenized with lysis buffer and sonicated using a Branson Sonifier 250 (All-spec, Wilmington, NC, USA) with set to 4 of output power for $10 \mathrm{sec}$. The lysates were then centrifuged at $8,000 \mathrm{rpm}$ for $5 \mathrm{~min}$ at $4^{\circ} \mathrm{C}$. The supernatant, containing cytosol and membrane, was centrifuged at $15,000 \mathrm{rpm}$ for $60 \mathrm{~min}$ at $4^{\circ} \mathrm{C}$, and were divided into cytosol and membrane. The pellet, containing the nucleus, was homogenized with lysis buffer and sonicated for $10 \mathrm{sec}$. It was centrifuged at 15, $000 \mathrm{rpm}$ for $15 \mathrm{~min}$ at $4{ }^{\circ} \mathrm{C}$ and the supernatant was collected as a nuclear lysate fraction.

\section{SDS-PAGE and Western blot analysis}

hUCB-MSCs were washed twice with cold-PBS followed by incubation on ice. Cells were lysed with lysis buffer (20 mM Tris [pH 7.5], 1 mM EDTA, 1 mM EGTA, 1\% Triton X-100, 1 mg/mL aprotinin, 1 mM PMSF, and $0.5 \mathrm{mM}$ sodium orthovanadate) [34] and shared with 1 set of 3-second pulses on ice using a Branson Sonifier 250 with set to 3 of output power. Sample protein separations were resolved by SDSpolyacrylamide gel electrophoresis (SDS-PAGE) and transferred to polyvinylidene difluoride (PVDF) membranes. The membranes were incubated with primary antibody (1:800 or $1: 1,000$ dilutions) at $4{ }^{\circ} \mathrm{C}$ incubator for overnight after blocked with TBST (10 mM Tris- $\mathrm{HCl}$ [pH 7.6], $150 \mathrm{mM} \mathrm{NaCl}$, and $0.01 \%$ Tween-20) containing 5\% skim milk for $1 \mathrm{~h}$. Next day, the membranes were washed with TBST and then incubated with a HRP secondary antibody. The specific bands were detected by ChemiDoc ${ }^{\mathrm{TM}}$ XRS+ System (Bio-Rad, Richmond, CA).

\section{Chromatin Immunoprecipitation assay}

EZ-ChIP-Chromatin Immunoprecipitation Kit (EMD Millipore) was used for Chromatin Immunoprecipitation (CHIP) assay. Cells were cross-linked by incubation at room temperature with $37 \%$ formaldehyde for $10 \mathrm{~min}$ and added $1 \mathrm{M}$ glycine to quench the unreacted formaldehyde according to the manufacturer's instructions. Fixed cells were harvested in SDS lysis buffer (1\% SDS, 10 mM EDTA, 50 mM Tris [pH 8.1] and protease inhibitors). Cell lysates were sonicated, and then were incubated with protein G beads (50\% protein G agarose slurry) for IP. IP included positive control (Anti-RNA polymerase II), negative control (IgG), and antibody of interest. The negative control IgG of the same species as the antibody of interest was used. Protein/DNA complexes were eluted by incubation at room temperature with elution buffer (20\% SDS, $1 \mathrm{M} \mathrm{NaHCO}_{3}$ and distilled water) for $15 \mathrm{~min}$. After centrifugation, supernatant was collected into new microfuge tubes. All IPs and inputs with $5 \mathrm{M} \mathrm{NaCl}$ were incubated at $65^{\circ} \mathrm{C}$ for overnight to reverse the protein/DNA cross-links. The purified DNA was subjected to PCR and DNA fragments were run on agarose gel $(2.5 \%)$ to facilitate quantitation of the PCR products. The sequences of the primers used in the PCR reactions were as follows: E-box human promoter (forward primer) 5' CTC CAG CTT GGG TGA AAG AG 3', E-box human promoter (reverse primer) 5' GGG CTT TTA CAC TTG GCT GA 3'.

Immunofluorescence staining

hUCB-MSCs were cultured in confocal dish. Cells were washed twice with cold-PBS, and then were fixed with 4\% PFA for 10 min according to previous report [36]. 0.1\% Triton X-100 diluted in PBS was used 
for permeabilization for 5 min. 5\% Normal Goat Serum (NGS) was used to decrease non-specific binding of antibody for $30 \mathrm{~min}$, followed by incubation with primary antibody with dilution of 1:100 for overnight. Subsequently, cells were incubated with either fluorescein isothiocyanate (FITC) conjugated anti-rabbit and -mouse IgG antibody or Alexa Fluor ${ }^{\circledR}$ goat anti-rabbit IgG to either propidium iodide (PI) or phalloidin in dark for $1 \mathrm{~h}$. Next, cells were observed using Eclipse Ts2-FL microscope (Nikon Corporation, Tokyo, Japan).

Real-time reverse transcriptase-polymerase chain reaction (RT-PCR)

Total RNA was extracted with an RNeasy Extraction Kit(Takara Bio, Shiga, Japan). RNA was quantified and a reverse transcription was performed with $1 \mu \mathrm{g}$ of RNA using a Maxime RT premix kit (iNtRON Biotechnology, Sungnam, Korea). Next, cDNA was amplified by specific primers using a PCR kit (iNtRON Biotechnology, Sungnam, Korea). mRNA was then performed in a Rotor-Gene 6500 real-time thermal cycling system (Corbett Research, Sydney, Australia) using the SYBR Green (Takara Bio, Shiga, Japan). The sequences of primers used for RT-PCR were as follows: Osteopontin 5'-GCCGAGGTGATAGTGTGGTT-3' and 5'-AACGGGGATGGCCTTGTATG-3'; Runx2 5'-TGGTTAATCTCCGCAGGTCAC-3' and 5'-ACTGTGCTGAAGAGGCTGTTTG-3'; Sox9 5'-AGTCGGTGAAGAACGGGCA-3' and 5'-AAGTCGATAGGGGGCTGTCTG-3'; FABP4 5'-CGTGGAAGTGACGCCTTTCATG-3' and 5'-ACTGGGCCAGGAATTTGACGAA-3'; PECAM1 5'-GGACCCTCGTGGATGTTGTA-3' and 5'-CTGCTCGGTTCTCTCTGTGA-3'; ULK1 5'-CAGAACTACCAGCGCATTGA-3' and 5'-TCCACCCAGAGACATCTTCC-3'; ULK2 5'-CTCCTCAGGTTCTCCAGTGC-3' and 5'-TTGGTGGGAGAAGTTCCAAG-3'; Atg14 5'-TCACCATCCAGGAACTCACA-3' and 5'-TTCAGTCTTCGGCTGAGGTT-3';Atg55'-CGGGAACACCAAGTTTCACT-3' and 5'-TCTGGGGAGACATCCGTAAG-3'; Atg12 5'-TGGGATTGCAAAATGACAGA-3' and 5'-TTCCCCATCTTCAGGATCAA-3'; Atg16L 5'-GTCTTCGATGCACATGATGG-3' and 5'-GATTCGGCTTGCAAAATCA-3'; $\beta$-actin 5'-AACCGCGSGSSGSTGACC-3, and 5'-AGCAGCCGTGGCCATCTC-3'.

\section{Phalloidin staining}

Human UCB-MSCs were cultured in confocal dish. Cells were washed twice with cold-PBS, and then were fixed with $4 \%$ PFA for 10 min. Subsequently, cells were permeabilized with $0.1 \%$ Triton X-100 in PBS for $5 \mathrm{~min}$. After blocking with $1 \%$ FBS or $5 \%$ normal goat serum for $30 \mathrm{~min}$, cells were incubated with Alexa Fluor 488-conjugated to phalloidin (Invitrogen Co., Carlsbad, CA) in dark for $1 \mathrm{~h}$. Cells were washed twice with PBS. Next, cells were observed using Eclipse Ts2-FL microscope (Nikon Corporation, Tokyo, Japan).

\section{Trichloroacetic Acid (TCA) precipitation}

The $10 \%$ TCA was added to $1 \mathrm{~mL}$ of hUCB-MSC culture media. The mixture was centrifuged at 14, 000 rpm for $5 \mathrm{~min}$ and the supernatant removed. The pellet was washed with $200 \mu \mathrm{L}$ cold acetone and then dried by using heat block at $95^{\circ} \mathrm{C}$ for $5 \mathrm{~min}$. Sample buffer was added to the pellet and the mixture boiled in heat block for $10 \mathrm{~min}$. Samples were loaded into polyacrylamide gel for SDS-PAGE electrophoresis.

\section{Statistical analysis}

Data are represented as mean \pm standard error mean (SEM). Statistical analyses were performed using the analysis of variance (ANOVA), and Bonferroni-Dunn test allows for multiple comparisons in some cases. A $p$ value of $<0.05$ was accepted as statistical significance.

\section{Results}

Effects of high glucose on migration and effects of hUCB-MSCs on mouse skin wound healing

To confirm the effect of high glucose on hUCB-MSC migration, cells were incubated under high glucose conditions for various concentrations of D-glucose or L-glucose from 5 to $50 \mathrm{mM}$ and for times ranging from 0 to $24 \mathrm{~h}$. D-glucose increased the number of migrating cells after cell incubation for $24 \mathrm{~h}$, while L-glucose did not have an effect on the cells (Fig. 1A), suggesting that the osmotic effect did not influence high glucose on hUCB-MSC migration. We also quantified the percent migration by using the Oris ${ }^{\mathrm{TM}}$ cell migration assay and observed a maximum increase of up to 151\% after incubating cells with $25 \mathrm{mM}$ D-glucose for $24 \mathrm{~h}$ 
Fig. 1. Effects of high glucose on migration and effects of hUCBMSCs on mouse skin wound healing. (A) Dose response effects of D-glucose (5-50 mM) or L-glucose (5-50 $\mathrm{mM}$ ) for $24 \mathrm{~h}$, and (B) time (0-24 h) response effects of high glucose (D-glucose, $25 \mathrm{mM}$ ) or normal physiological conditions of glucose ( $5 \mathrm{mM}$ ) on hUCB-MSC migration were measured with Oris ${ }^{\mathrm{TM}}$ cell migration assay. hUCB-MSCs cultured with normal medium were regarded as the control. $\mathrm{n}=$ 3. ${ }^{*} \mathrm{p}<0.05$ versus $5 \mathrm{mM}$ D-glucose. (C) Wound healing migration assay was performed in the presence of high glucose $(25 \mathrm{mM})$ and with the IBIDI $^{\mathrm{TM}}$ cell culture inserts. Cells were treated with $25 \mathrm{mM}$ glucose for various time periods $0-24$ h). Wound width $=500 \mu \mathrm{m}$. Scale bars $=100 \mu \mathrm{m}$. (D) Cells were pretreated with $1 \mu \mathrm{g} / \mathrm{mL}$ mitomycin C for $90 \mathrm{~min}$ prior to $25 \mathrm{mM}$ glucose

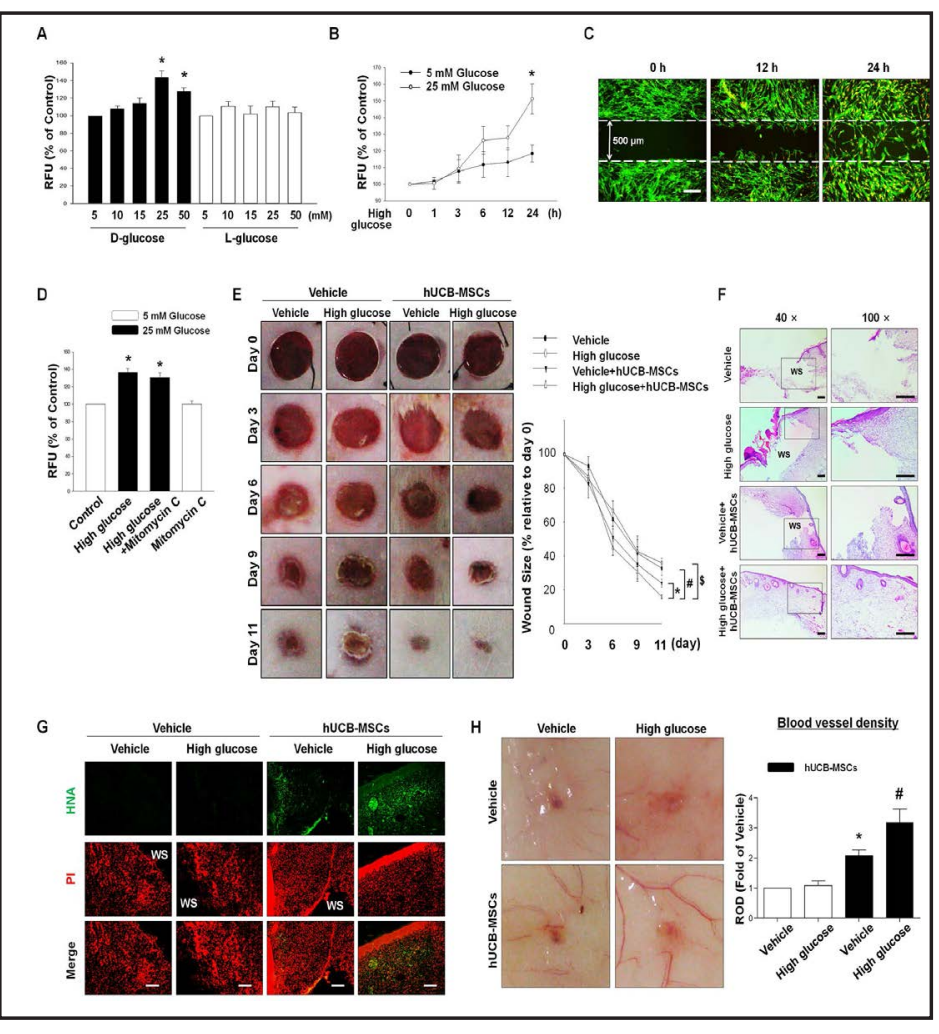
treatment for $24 \mathrm{~h}$. Fluorescence in the analytical zone was quantified with a plate reader. $n=3 .{ }^{*} p<0.05$ versus control. (E) Representative gross images of wounds at days $0,3,6,9$, and 11 are shown (left panel). Wound sizes were measured using Image J (right panel). $\mathrm{n}=6$ each group. ${ }^{*} \mathrm{p}<0.05$ versus vehicle + hUCB-MSC group. $\# \mathrm{p}<0.05$ versus vehicle group. $\$ \mathrm{p}<0.05$ versus high glucose group. (F) Wound tissues were stained by using H\&E staining at day 11 after wounding. Scale bar $=200 \mu \mathrm{m}$ or $100 \mu \mathrm{m}$, magnification; $\times 40$ or $\times 100$. (G) Wound tissues were immunostained with HNA (green) and PI (red). Scale bar $=50 \mu \mathrm{m}$. $(\mathrm{H})$ Representative gross images of blood vessels in wound site at day 11 are shown (left panel). Blood vessel density was analyzed by optical density using Image J (right panel). ${ }^{*} \mathrm{p}<0.05$ versus vehicle group, $\# \mathrm{p}<0.05$ versus vehicle + hUCB-MSCs group. Abbreviations: RFU, relative fluorescence units; ROD, relative optical density; WS, wound site; HNA, human nuclear antigen.

(Fig. 1B). High glucose also facilitated hUCB-MSCs migration to the detection zone (Fig 1C). As shown (for all online suppl. material, see www.karger.com/doi/10.1159/000489360) in suppl. Fig. S1, high glucose induced F-actin cytoskeleton reorganization, and formed cellmotility structures at the leading edges of the cells. The cytoskeleton changes occurred at various time periods by high glucose in hUCB-MSCs. In order to distinguish cell migration from proliferation, cells were pretreated with Mitomycin $\mathrm{C}$ to inhibit cell proliferation. As a result, we observed no significant differences between the groups treated with or without Mitomycin $\mathrm{C}$ under high glucose conditions. This means that high glucose-induced hUCB-MSC proliferation did not affect hUCB-MSC migration (Fig. 1D). Additionally, we also examined the expressions of mRNA and protein in hUCB-MSCs to determine whether high glucose induced differentiation (Osteopontin, Runx2, Sox9, FABP4, and PECAM1), senescence (p16 and p21), and autophagy (ULK1, ULK2, Atg14, Atg5, Atg12, Atg16L, and LC3). The mRNA expression levels of differentiation marker genes were not significantly changed for $24 \mathrm{~h}$ in hUCB-MSCs. In addition, p16 and p21 expression levels did not change under high glucose conditions. Furthermore, the mRNA expression levels of autophagy marker and LC3 protein expression levels were not significantly changed. Therefore, hUCB-MSCs used in our study have remained undifferentiated, and senescence or autophagy did not occur by high glucose 
(see online suppl. material, Suppl. Fig. S2). In addition, other sources of MSCs, AD-MSCs, significantly stimulated the migration after incubating cells with $25 \mathrm{mM}$ glucose for $24 \mathrm{~h}$ (see online suppl. material, Suppl. Fig. S3). In order to investigate the wound healing effect of high glucose-pretreated hUCB-MSCs, we used a mouse skin excisional wound splinting model and performed wound size measurements, histological examinations, and blood vessel density measurements. The wound area of the high glucose-pretreated hUCB-MSC group compared to that of the hUCB-MSC alone was significantly reduced at 11 days after wounding as well as the wound area of hUCB-MSC transplanted groups compared to basal conditions (Fig. 1E). Histological examination of wound tissues on day 11 showed that the wound site was completely filled with granulation tissues by high glucose pretreated hUCBMSCs transplantation compared to the wounds of vehicle, high glucose, or hUCB-MSC group (Fig. 1F). To track transplanted hUCB-MSCs in vivo on day 11, wound tissues were stained with anti-human nuclear antigen (HNA) antibody. Immunohistochemistry revealed many HNA-positive cells in high glucose-pretreated hUCB-MSC group, whereas in vehicle or high glucose group, no HNA-positive cells were found (Fig. 1G). Blood vessels that developed many branches were observed in hUCB-MSC transplanted groups compared to the vehicle or high glucose treated group (Fig. 1H). Collectively, the data suggest that hUCB-MSCs cultured with high glucose significantly increased migratory activity compared to those cultured at a normal physiological glucose level. Moreover, high glucose-pretreated UCBMSC transplantation significantly accelerated skin wound healing.

Fig. 2. Effect of high glucose on Ecadherin, Notch, Snail and EZH2 in hUCB-MSCs.

Expression of Ecadherin was analyzed by western blotting with a specific antibody. The cells were exposed to high glucose for 0 to $48 \mathrm{~h}$, and the total lysates were analyzed by western blotting with antiE-cadherin antibody. $\beta$-actin was

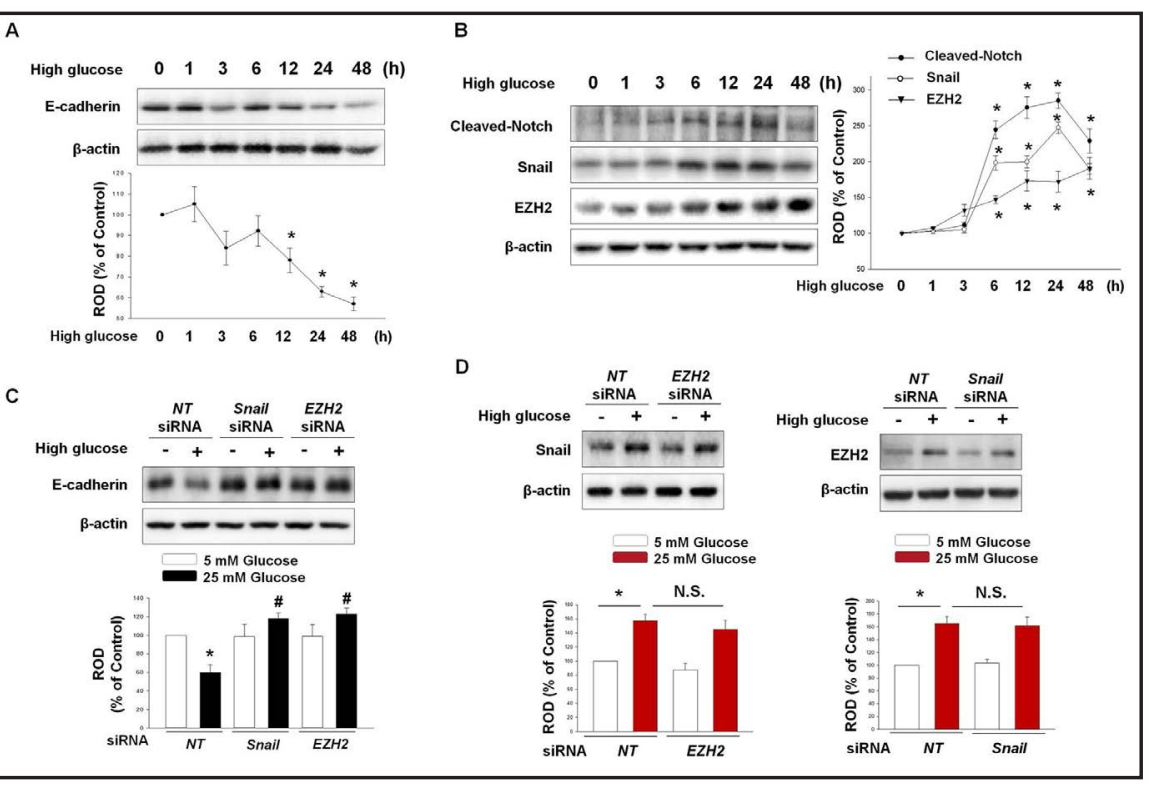
used as a loading control. $n=3$. ${ }^{*} \mathrm{p}<0.05$ versus $0 \mathrm{~h}$. (B) hUCB-MSCs were incubated under high glucose conditions for 0 to 48 $\mathrm{h}$, and the total cell lysates were analyzed by western blot with antibodies that recognize cleaved-Notch, Snail and EZH2. $\beta$-actin was used as a loading control. $n=3 .{ }^{*} p<0.05$ versus 0 h. (C) Cells were treated with $N T$-, Snail- or EZH2 siRNA in presence or absence of $25 \mathrm{mM}$ glucose. E-cadherin was analyzed by western blotting. $\mathrm{n}=3 .{ }^{*} \mathrm{p}<0.05$ versus NT siRNA only and $\# \mathrm{p}<0.05$ versus high glucose with $N T$ siRNA transfection. (D) hUCB-MSCs were left untransfected or transfected with NT siRNA or specific siRNA that silences EZH2 or Snail expression and then treated for a further $24 \mathrm{~h}$ with $25 \mathrm{mM}$ glucose. $\mathrm{n}=3$. ${ }^{*} \mathrm{p}<0.05$ versus NT siRNA only. N.S. = non-significant $(\mathrm{p}>0.05)$. Abbreviations: NT siRNA, non-targeting small interfering RNA; ROD, relative optical density. 
Effect of high glucose on E-cadherin, cleaved Notch, Snail and EZH2 expressions

Because regulation of E-cadherin expression plays an important role in cell migration, we investigated the effect of high glucose-induced E-cadherin repression in hUCB-MSCs. Human UCB-MSCs were incubated at high glucose conditions for up to $48 \mathrm{~h}$ to verify E-cadherin expression and to examine whether high glucose affected E-cadherin, which is related with hUCB-MSC migration. E-cadherin expression decreased gradually after $12 \mathrm{~h}$ incubation under high glucose conditions (Fig. 2A). In addition, cleaved-Notch, Snail and EZH2 expressions were increased in a time-dependent manner under high glucose conditions (Fig. 2B). To confirm the role of high glucose-induced E-cadherin by regulating Snail and EZH2 expressions, NT, Snail, and EZH2 siRNA transfections were carried out. The levels of E-cadherin were reduced by NT siRNA while Snail and EZH2 siRNA restored the E-cadherin level under high glucose conditions (Fig. 2C). To confirm the signaling relationship between Snail and EZH2, Snail and

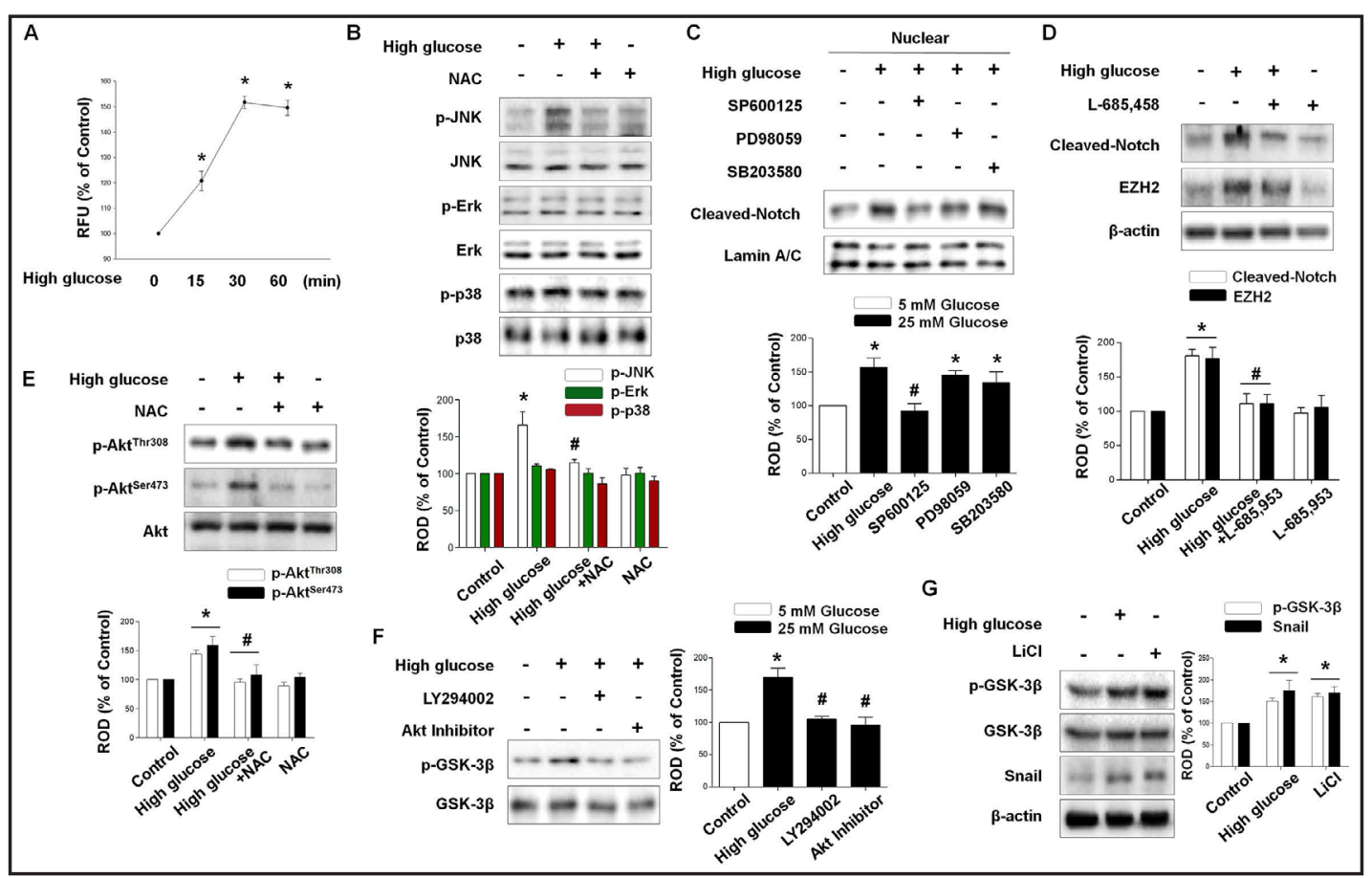

Fig. 3. Role of ROS-dependent Notch signaling pathway and ROS-dependent PI3K/Akt/GSK-3 $\beta$ signaling pathway (A) The cells were incubated in high glucose conditions for 0 - $60 \mathrm{~min}$. Dichlorofluorescein-sensitive cellular ROS was detected by luminometer. $n=3$. ${ }^{*} \mathrm{p}<0.05$ versus 0 min. (B) NAC (ROS inhibitor; $10 \mu \mathrm{M}$ ) was used for pretreatment prior to incubation in the high glucose conditions. p-JNK, p-Erk or p-p38 was detected following SDS-PAGE. $\mathrm{n}=3 .{ }^{*} \mathrm{p}<0.05$ versus control of $\mathrm{p}$-JNK. $\# \mathrm{p}<0.05$ versus high glucose alone of p-JNK. (C) The cells were pretreated with SP600125 (JNK inhibitor; $1 \mu \mathrm{M}$ ), PD98059 (Erk inhibitor, $10 \mu \mathrm{M}$ ), or SB203580 (p38 MAPK inhibitor, $1 \mu \mathrm{M}$ ) for 30 min before incubation under high glucose conditions, and then, the nuclear fractions were isolated from cells as described in the "Materials and Methods". Lamin $\mathrm{A} / \mathrm{C}$ was used as a nuclear marker. $\mathrm{n}=3$. ${ }^{*} \mathrm{p}<0.05$ versus control. $\# \mathrm{p}<0.05$ versus high glucose alone. (D) L-685,458 ( $\gamma$-secretase inhibitor; $10 \mu \mathrm{M}$ ) was used for pretreatment prior to incubation under high glucose conditions for $24 \mathrm{~h}$. Cleaved-Notch, Snail and EZH2 were detected following SDS-PAGE. $\mathrm{n}=3$. ${ }^{*} \mathrm{p}<0.05$ versus control. $\# \mathrm{p}<0.05$ versus high glucose alone. (E) The cells were pretreated with NAC prior to incubation under high glucose conditions for 180 min. p-Akt ${ }^{\text {The308 }}$, p-Akt ${ }^{\text {Ser473 }}$, or Akt was analyzed by western blotting. $\mathrm{n}=3$. ${ }^{*} \mathrm{p}<0.05$ versus control, \#p<0.05 versus high glucose alone. (F) The cells were pretreated with LY294002 (PI3K inhibitor; $1 \mu \mathrm{M})$, or Akt inhibitor $(10 \mu \mathrm{M})$ prior to incubation under high glucose conditions, and p-GSK-3 $\beta$ and GSK-3 $\beta$ were detected. $n=3 .{ }^{*} p<0.05$ versus control, $\# p<0.05$ versus high glucose alone. (G) hUCB-MSCs were treated with $\mathrm{LiCl}(10 \mathrm{mM})$ for $30 \mathrm{~min}$. The total cell lysates were analyzed by western blotting using antibodies that recognized p-GSK-3 $\beta$, GSK-3 $\beta$ and Snail. $n=3$. ${ }^{*} \mathrm{p}<0.05$ versus control. Abbreviations: p, phosphorylation; RFU, relative fluorescence units; ROD, relative optical density. 
EZH2 siRNA transfections were carried out. Interestingly, the protein levels of Snail were not reduced by EZH2 siRNA, and the levels of EZH2 were not reduced by Snail siRNA (Fig. 2D). Hence, these results indicate that high glucose-induced E-cadherin repression is regulated by Snail and EZH2, and Snail is regulated in parallel with EZH2 by high glucose.

Role of ROS-stimulated JNK/Notch and PI3K/Akt/GSK-3 3 pathways in high glucoseinduced EZH2 and Snail expressions

High glucose stimulation is well known to increase the ROS production. To examine the effect of high glucose on ROS generation in hUCB-MSCs, high glucose-induced ROS generation was examined using DCF-DA, to gradually increase ROS generation (Fig. 3A). The activation of mitogen activated protein kinase (MAPK) and Akt pathways play important roles in migration induction under high glucose conditions [40, 41]. Thus, we further investigated whether high glucose-induced ROS can modulate the MAPK regulation. High glucose significantly enhanced the JNK activation at $180 \mathrm{~min}$ while phosphorylation levels of Erk and p38 MAPK had no time-related changes (see online suppl. material, Suppl. Fig. S4A). Blockage of ROS in hUCB-MSCs under high glucose conditions led to decreased JNK activation compared to high glucose alone. However, ROS inhibition with NAC treatment did not lead to the inhibition of phosphorylation of Erk and p38 MAPK (Fig. 3B). Furthermore, high glucose-induced hUCB-MSC migration was blocked by NAC or SP600125 (see online suppl. material, Suppl. Fig. S4B). In order to investigate whether ROS-induced p-JNK in high glucose conditions regulates $\gamma$-secretase in hUCB-MSCs, we performed western blotting after isolating the nuclear fraction. In the nucleus, cleaved-Notch was down-regulated after treating hUCB-MSCs with SP600125. However, pretreatment with PD98059 and SB203580 did not impact the cleaved-Notch as well as the degradation of cleaved-Notch after SP600126 treatment in high glucose conditions in the nucleus (Fig. 3C). Furthermore, high glucose elevated the expression of EZH2, which was suppressed by the L-685, 458 (Fig. 3D). These results show that ROS-mediated JNK activation regulated $\gamma$-secretase-induced Notch cleavage for Notch intracellular domain (NICD) under high glucose conditions.

To assess whether high glucose-induced ROS production can regulate PI3K/Akt and GSK-3 $\beta$ signaling pathways, we measured the total expression and activation of Akt and GSK$3 \beta$. Akt ${ }^{\text {thr308 }}$ and $A k t^{\text {ser473 }}$ phosphorylation were gradually increased by incubation in high glucose conditions (see online suppl. material, Suppl. Fig. S4C). In addition, NAC blocked high glucose-induced Akt ${ }^{\text {thr308 }}$ and Akt ${ }^{\text {ser473 }}$ phosphorylation, which suggest that high glucoseinduced activation of Akt at thr308 and ser473 was regulated by ROS (Fig. 3E). We next investigated whether PI3K/Akt signaling induced phosphorylation of GSK-3 $\beta$. In high glucose conditions, the inhibitions of PI3K/Akt with LY294002 or the Akt inhibitor blocked GSK-3 $\beta$ phosphorylation (Fig. 3F), resulting in subsequent Snail stabilization. As shown in the details (see online suppl. material) of Suppl. Fig. S4D, although the total expression levels of GSK-3 $\beta$ were unmodified by high glucose, the level of GSK- $3 \beta$ phosphorylation increased in a timedependent manner. In order to determine whether high glucose increased Snail expression through GSK-3 $\beta$ phosphorylation, the cells were pretreated with $\mathrm{LiCl}$, a well-known GSK$3 \beta$ inhibitor. LiCl increased the inactive phosphorylated form of GSK-3 $\beta$ at ser9 [42] and Snail expression (Fig. 3G). These results suggest that high glucose-induced ROS regulates the activation of PI3K/Akt signaling to inhibit GSK-3 $\beta$. The GSK-3 $\beta$ inhibition induces an increase in Snail stabilization.

Effect of high glucose on the formation of EZH2/Snail/HDAC1 complex in the nucleus

Next, we examined the role of high glucose-induced Snail and EZH2 accumulation in the nucleus. To determine the cellular fraction where cleaved-Notch, Snail, and EZH2 accumulated, we tested the nuclear and cytosolic fraction before performing a western blot analysis. High glucose enriched cleaved-Notch, Snail, and EZH2 in the nuclear fraction. While the cytoplasmic levels of cleaved-Notch did not change, the cytoplasmic levels of Snail and EZH2 increased (Fig. 4A). Immunofluorescence staining indicated that Snail or EZH2 present in the cytoplasm accumulated around the nucleus and translocated to the nucleus 


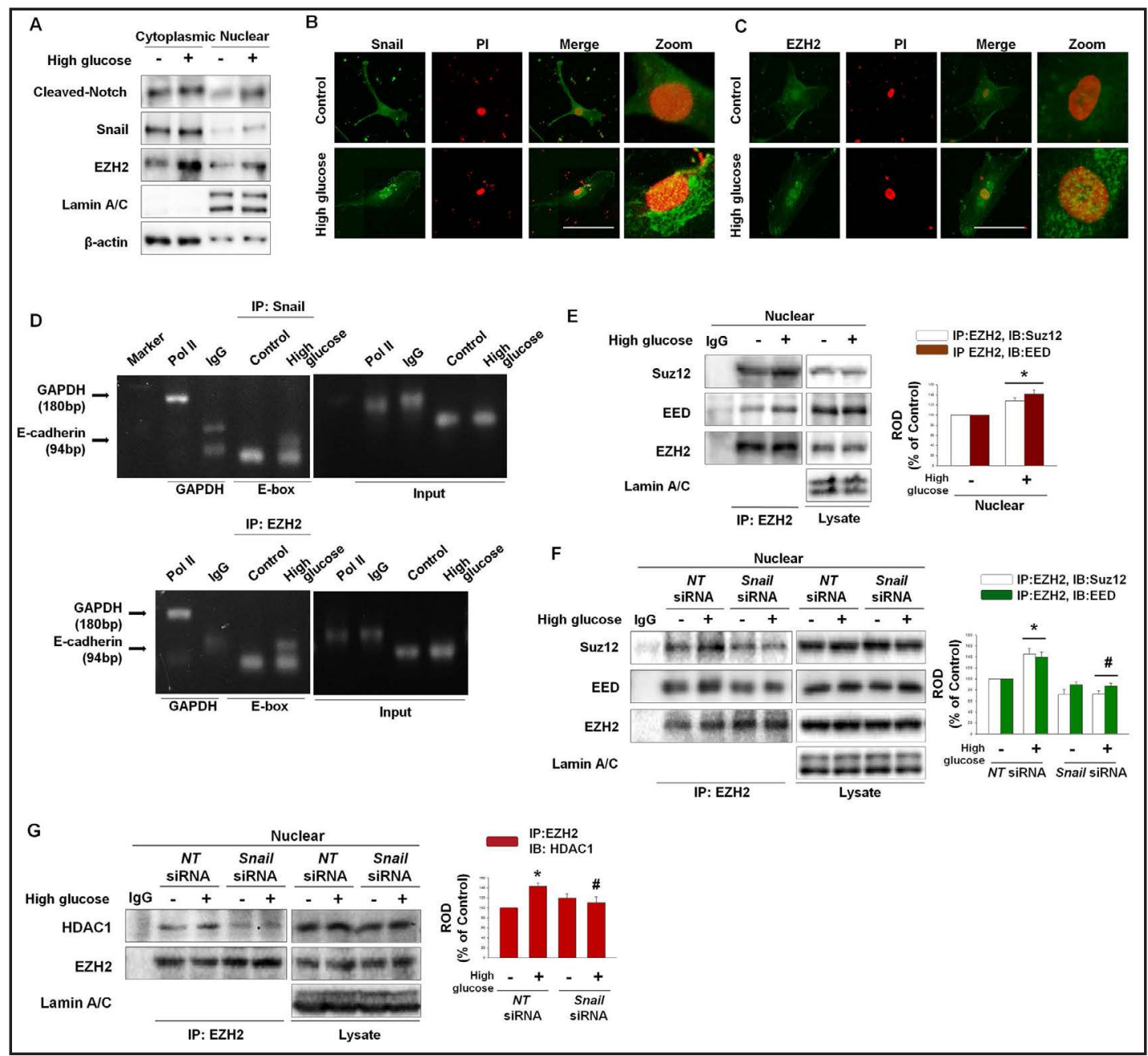

Fig. 4. Role of high glucose-induced Snail and EZH2 in the nucleus. (A) hUCB-MSCs were incubated under high glucose conditions for $24 \mathrm{~h}$, and the lysate were fractionized into the cytosol and nuclear parts. The fractions were subjected to SDS-PAGE, and expression levels of cleaved-Notch, Snail and EZH2 were detected. Lamin $\mathrm{A} / \mathrm{C}$ were used as a nuclear marker and $\beta$-actin were used as a cytosolic marker, respectively. $n=3$. (B, C) Cells were stained with Snail and EZH2 antibody and counterstained with PI. Fluorescence density of Snail and EZH2 in the cellular region was confirmed by fluorescence microscopy. Scale bars $=50 \mu \mathrm{m}$, magnification; $\times$ 400. (D) hUCB-MSCs were cross-linked with formaldehyde directly in the culture medium after treatment with high glucose for $24 \mathrm{~h}$. DNA was sheared and immunoprecipitated with an anti-Snail and anti-EZH2 antibody. After reversing the cross-linking, the DNA was amplified using the E-cadherin primer, CDH-1. (E) Immunoassay of nuclear extracts of hUCB-MSCs was left untreated or incubated with high glucose, assessed by IP with anti-EZH2 (IP: EZH2) or without IP (lysate), followed by IB analysis (IB: Suz12 and EED). $n=3$. ${ }^{*} \mathrm{p}<0.05$ versus control. (F) Immunoassay of nuclear extracts of hUCB-MSCs was left transfected with NT siRNA or specific siRNA that silence Snail expression and then was treated for $24 \mathrm{~h}$ with $25 \mathrm{mM}$ glucose, assessed by IP with anti-EZH2 or without IP (lysate), followed by IB (PRC2 components). n=3. *p $<0.05$ versus NT siRNA only. \#p<0.05 versus high glucose with $N T$ siRNA transfection. (G) Immunoassay of nuclear extracts of hUCB-MSCs was left transfected with NT siRNA or specific siRNA that silence Snail expression and then treated for a further $24 \mathrm{~h}$ with $25 \mathrm{mM}$ glucose, assessed by IP with anti-EZH2 or without IP (lysate), followed by IB (HDAC1). $\mathrm{n}=3 .{ }^{*} \mathrm{p}<0.05$ versus NT siRNA only. $\# \mathrm{p}<0.05$ versus high glucose with NT siRNA transfection. Abbreviations: ROD, relative optical density.

under high glucose conditions (Fig. 4B and C). To examine whether Snail and EZH2 are required for binding to the E-box of the E-cadherin promoter under high glucose conditions,

\section{KARGER}


Fig. 5. High glucose regulates E-cadherin expression and UCBMSC migration and role of Snail and EZH2 on enhancing the therapeutic efficacy in repairing skin wound. (A) The cells were incubated in 5 $\mathrm{mM}$ glucose (control), $25 \mathrm{mM}$ glucose (high glucose), $25 \mathrm{mM}$ glucose with either NAC, SP600125, L-685,458 or LY294002, LiCl for $24 \mathrm{~h}$, and E-cadherin was analyzed by western blotting. $n=3$. ${ }^{*} \mathrm{p}<0.05$ versus control and $\# \mathrm{p}<0.05$ versus high glucose alone. (B) Oris $^{\mathrm{TM}}$ migration assay was performed with cells pretreated with L-685,458, LY294002, LiCl, EZH2-, and Snailspecific siRNA prior to treatment of high glucose for 24 h. Fluorescence in the analytical zone was quantified with a plate reader. $\mathrm{n}=3 . \quad * \mathrm{p}<0.05$ versus control and $\# \mathrm{p}<0.05$

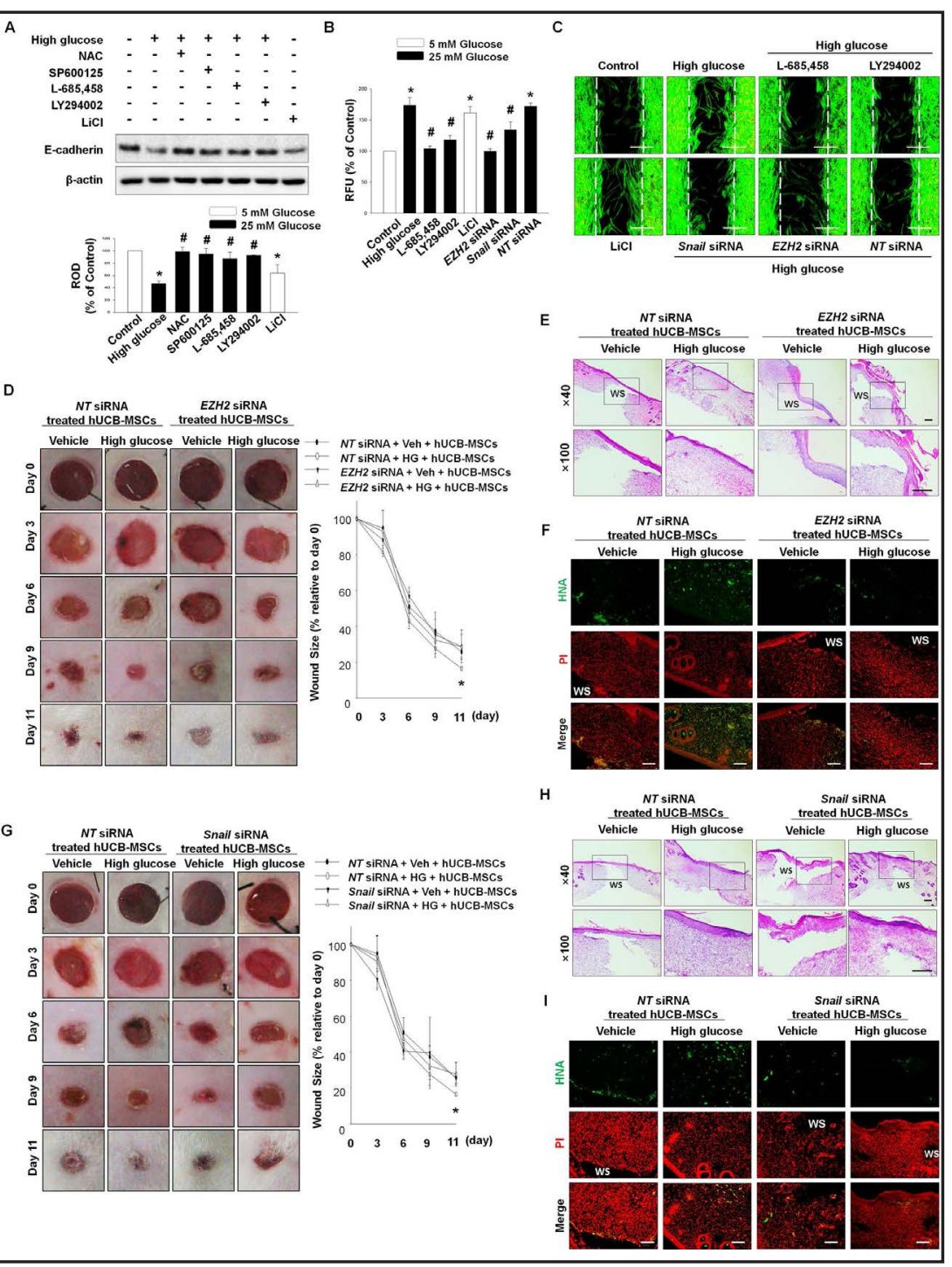
versus high glucose

alone. (C) Wound healing assay was performed with the pretreatment of L-685,458, LY294002, LiCl, EZH2, Snail- specific siRNA, and NT siRNA in the presence/absence of high glucose. Scale bars $=200 \mu \mathrm{m}$. (D) Representative gross images of wounds at days $0,3,6,9$, and 11 are shown (left panel). Wound sizes were measured using Image $\mathrm{J}$ (right panel). $\mathrm{n}=6$ each group. ${ }^{*} \mathrm{p}<0.05$ versus $N T$ siRNA + Vehicle + hUCB-MSCs group. (E) Wound tissues were stained by using H\&E staining at day 11 after wounding. Scale bar $=200 \mu \mathrm{m}$ or $100 \mu \mathrm{m}$, magnification; $\times 40$ or $\times 100$. (F) Wound tissues were immunostained with HNA (green) and PI (red). Scale bar $=50 \mu \mathrm{m}$. (G) Representative gross images of wounds at days $0,3,6,9$, and 11 are shown (left panel). Wound sizes were measured using Image J (right panel). $\mathrm{n}=6$ each group. ${ }^{*} \mathrm{p}<0.05$ versus NT siRNA + vehicle + hUCB-MSCs group. $(\mathrm{H})$ Wound tissues were stained by using H\&E staining at day 11 after wounding. Scale bar $=200 \mu \mathrm{m}$ or $100 \mu \mathrm{m}$, magnification; $\times 40$ or $\times 100$. (I) Wound tissues were immunostained with HNA (green) and PI (red). Scale bar $=50 \mu \mathrm{m}$. Abbreviations: ROD, relative optical density; HG, high glucose; Veh, vehicle; WS, wound site; HNA, human nuclear antigen.

we performed CHIP to analyze whether Snail and EZH2 were recruited to the E-cadherin promoter. The CHIP assays revealed that high glucose enhanced the interaction between Snail and the E-cadherin promoter. In addition, the interaction between EZH2 and the E-cadherin promoter was also enhanced by high glucose (Fig. 4D). To determine the effect of high glucose on PRC2 complex formation, we evaluated the effect of high glucose on co-IP of 
EZH2 and Suz12, or EZH2 and EED. Suz12 or EED were co-immunoprecipitated with EZH2 by high glucose in the nucleus (Fig. 4E). In addition, Snail was also able to associate with the PRC2 complex by high glucose (see online suppl. material, Suppl. Fig. S5). Subsequently, to examine the relationship between Snail and PRC2 by high glucose, hUCB-MSCs were transfected with Snail siRNA prior to incubation for $24 \mathrm{~h}$ in high glucose conditions. In the nucleus, high glucose enhanced the EZH2 and Suz12, or EZH2 and EED complex. However, Snail siRNA disrupted the interaction between EZH2 and Suz12, or EZH2 and EED (Fig. 4F), suggesting that Snail is required to bind the complexes and has important functions in hUCBMSC migration. Interestingly, it has been reported that Snail is associated with the PRC2 complex for the repression of E-cadherin by the recruitment of HDAC [43], so the Snail was checked to see if it controlled the action of HDAC. As shown in Fig. 4G, binding HDAC1 with the major component of PRC2, EZH2, was increased under high glucose conditions, whereas Snail-knockdown hUCB-MSCs maintained the interaction between EZH2 and HDAC1. This suggests that the presence of HDAC1 is necessary to associate the Snail and PRC2 complex. These results demonstrate that Snail interacts with PRC2 by high glucose in the nucleus, and the complex binds with E-box of the E-cadherin promoter, which in turn causes the E-cadherin repression.

Role of high glucose-induced Snail and EZH2 in E-cadherin expression, migration and mouse skin wound healing efficacy

To examine the role of high glucose and its related signal molecules on hUCB-MSC migration, we pretreated the cells with NAC, SP600125, L-685, 458, and LY294002 prior to high glucose treatment in normal hUCB-MSC culture conditions. Pretreatment with NAC, SP600125, L-685, 458, or LY294002 restored the E-cadherin expression level that has been reduced by high glucose (Fig. $5 \mathrm{~A}$ ). The Oris ${ }^{\mathrm{TM}}$ cell migration assay was used to quantify the amount of migration. Consequently, high glucose-induced cell migration was inhibited by each signal pathway-related molecule inhibitor or siRNAs (Fig. 5B). The effects of high glucose were confirmed with the IBIDI ${ }^{\mathrm{TM}}$ culture insert dish assays (Fig. 5C). Furthermore, to evaluate the function of E-cadherin, transfection of E-cadherin siRNA was performed. Silencing E-cadherin enhanced hUCB-MSC migration, so E-cadherin affects the migration ability in hUCB-MSCs (see online suppl. material, Suppl. Fig. S6). To examine the relationship between Snail/EZH2 expression and skin wound healing effect of high glucose-pretreated hUCB-MSCs, we performed hUCB-MSC transplantation transfected with Snail or EZH2 siRNA into the wound sites in mice. The wounds of high glucose-pretreated EZH2 siRNA + hUCB-MSC group remained unrepaired as well as the structures of the epidermis and dermis, compared to the wounds of high glucose-pretreated NT siRNA + hUCB-MSC group (Fig. 5D and E). HNA-positive cells in the high glucose-pretreated EZH2 siRNA + hUCB-MSC group were not found much when compared to the high glucose-pretreated NT siRNA + hUCB-MSCs group (Fig. 5F). In addition, the wound area of Snail siRNA-treated hUCB-MSC group compared to the wounds of high glucose-pretreated NT siRNA + hUCB-MSC group did not heal 11 days after wounding (Fig. 5G). The histological examination of wound tissues observed that the wound site was completely filled with granulation tissues in high glucose-pretreated $N T$ siRNA + hUCB-MSCs group as opposed to the wounds of NT siRNA treated hUCB-MSC, Snail siRNA-treated hUCB-MSC, or the high glucose-pretreated Snail siRNA + UCB-MSC group (Fig. $5 \mathrm{E})$. Immunohistochemistry revealed that there were many HNA-positive cells in the high glucose-pretreated NT siRNA + hUCB-MSC group, whereas the wound tissues in NT siRNA treated hUCB-MSC, Snail siRNA-treated hUCB-MSC, or high glucose-pretreated Snail siRNA + UCB-MSC group contained much less HNA-positive cells (Fig. 5F). Thus, these results indicate that high glucose-pre-activated hUCB-MSC transplantation accelerates skin wound closure.

\section{Discussion}

In this study, we showed the effect of high glucose on enhancing the migration of hUCBMSC and the involvement of Notch signaling pathway, which contributes to E-cadherin 
repression through the interplay between Snail and EZH2. According to previous reports investigating cell migration under high glucose condition, the effect of glucose on cell migration still remains controversial depending on the cell types [14, 44, 45]. Our data in this study revealed that high glucose stimulates hUCB-MSC migration with suppression of E-cadherin expression. Moreover, we presented in vivo proof showing that high glucosepretreated hUCB-MSCs promoted the migration of transplanted cells into the wound site and accelerated the skin wound closure in a mouse excisional wound splinting model. Previous reports demonstrated that the augmentation of MSC migration to the wound site increases the efficacy of wound healing through beneficial effects [36, 46-49]. Thus, migration is considered to be an important factor of MSC-induced wound healing. E-cadherin degradation by netrin pretreatment enhances migratory ability of hUCB-MSCs [50]. The reduction of E-cadherin expression during cell migration can be controlled by epigenetic transcriptional regulation and post-transcriptional modification of transcription for the $C D H 1$ gene [51]. Our results investigating the effect of high glucose on E-cadherin and its epigenetic regulators showed that high glucose decreased the expression of E-cadherin via increasing the expressions of EZH2 and Snail. Epigenetic factors have key roles in modulating E-cadherin expression, and the epigenetic silencing of E-cadherin is mediated by histone-modifying enzymes including Snail1 and EZH2 [43, 52]. Based upon these findings, we suggest that epigenetic regulation of E-cadherin is a critical factor for high glucose-stimulated migration in hUCB-MSCs.

Extracellular glucose influences ROS formation as mediators of intracellular signaling cascades $[53,54]$. ROS acts as an intracellular messenger inducing a variety of intracellular events such as protein phosphorylation and gene expression [55-57]. Indeed, our results showed high glucose stimulated intracellular ROS production, and JNK phosphorylation was induced by high glucose-induced ROS. Similarly, it was reported that the motility of MSCs was promoted by ROS-induced MAPK phosphorylation under shear stress conditions while high glucose-induced ROS distinctively phosphorylated JNK in renal mesangial cells [58]. This observation may indicate that JNK activation is more responsive to high glucose treatment than Erk and p38 MAPK via high glucose-induced ROS dependent manner in hUCB-MSCs. Furthermore, we also showed that JNK phosphorylation stimulates $\gamma$-secretase-dependent Notch cleavage, leading to translocation of NICD into the nucleus. Previous reports demonstrated that JNK contributes to $\gamma$-secretase activation, but Erk1/2 acts as a negative regulator of $\gamma$-secretase activity $[59,60]$. These findings support our results that high glucose-induced p-JNK could trigger Notch signaling via $\gamma$-secretase activation. In addition, it was reported that high EZH2 expression is associated with increased Notch1 activation [61]. Furthermore, our data showed that pretreatment of $\gamma$-secretase inhibitor suppressed the high glucose-induced cleaved Notch and EZH2 expressions. Therefore, previous and present findings indicate Notch signaling activated by JNK could be involved in high glucoseinduced EZH2 expression.

Considering the regulatory mechanism of Snail by high glucose, previous reports demonstrated that the stabilization of Snail was regulated by the Akt/GSK-3 $\beta$ pathway [62, 63]. Our previous study revealed high glucose-induced ROS/PI3K/Akt pathway involving in functional regulation of stem cells [64]. Although previous research reported high glucoseactivated GSK-3 $\beta$ plays an inhibitory role in proliferation and migration of bone marrowderived MSCs [65], present data revealed that high glucose-induced ROS phosphorylates Akt, which subsequently induced Snail expression via GSK-3 $\beta$ inhibition in hUCB-MSCs. Consistent with our results, GSK-3 $\beta$ activation can maintain epithelial morphology by proteosomal degradation of Snail, thereby maintaining high E-cadherin expression $[66,67]$. Thus, we suggest that the Akt/GSK-3 $\beta$ pathway activated by high glucose is a major pathway upregulating Snail expression in hUCB-MSCs.

Previous reports have shown that epigenetic regulation is an important factor in the regulation of stem cell fate $[68,69]$. EZH2 has been considered an essential factor for epigenetic regulation of E-cadherin [43]. Binding of PRC2 members, such as EZH2, Suz12, and EED, to the promoter of target gene induces epigenetic regulation that is regulated by Snail, which cooperates with PRC2 [43, 52, 70, 71]. Snail is also required for EZH2-mediated 
Fig. 6. The hypothetical model for the proposed signaling network was involving in high glucose-induced hUCB-MSC migration. High glucose enhances ROS, which activates either JNK or PI3K/Akt signaling. High glucose-induced JNK activation stimulated $\gamma$-secretase, and elicits the cleavage of the Notch protein. NICD induced the EZH2 expression, and allows them to translocate to the nucleus. Stimulation of high glucose leads to an induction of phosphorylation of GSK-3 $\beta$ via the PI3K/Akt pathway, which leads to Snail stabilization. Once in the nucleus, EZH2 makes a complex with Suz12 and EED, and the complex associates with the E-box of the promoter regions of E-cadherin by Snail. These complexes have an inductive effect on hUCB-MSC migration by the repression of E-cadherin. NAC: ROS inhibitor; SP600125: JNK inhibitor; L-685, 458: $\gamma$-secretase inhibitor; LY294002: PI3K inhibitor; LiCl: GSK-3 $\beta$ inhibitor.

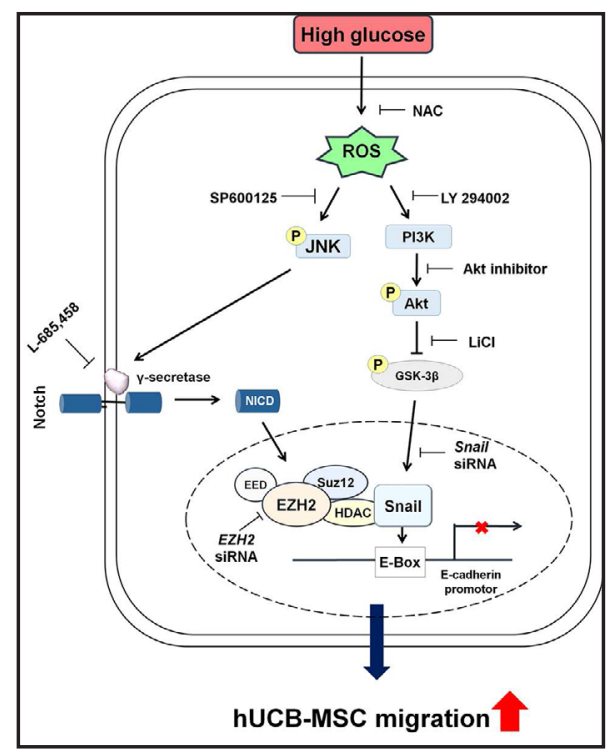

E-cadherin repression and the complex of EZH2/HDAC/Snail contributed to E-cadherin silencing in carcinomas $[72,73]$. In this study, high glucose stimulated Suz12/EED/EZH2 complex formation for E-cadherin inhibition, which was regulated by the high glucosestabilized Snail. In addition, several studies reported that Snail interacts with the HDAC to repress E-cadherin $[73,74]$. HDACs are enzymes that play crucial roles in the deacetylation of chromatin proteins and in the regulation of non-histone proteins for cellular homeostasis [75]. As intermediaries between Snail and PRC2, HDAC promotes PRC2 which links with Snail at the promoter region of E-cadherin [76]. Additionally, an overexpression of Snail stimulates recruitment of the HDAC1/HDAC2 complex, which leads to deacetylation of histone $\mathrm{H} 3$ and $\mathrm{H} 4$ at the $C D H 1$ promoter [73]. Indeed, our data showed that Snail induced by high glucose increases the interaction of HDAC1 with EZH2. This finding presents the possibility that high glucose-induced Snail regulates PRC2 activity to repress E-cadherin expression via HDAC1. Our data confirmed the regulatory effect of EZH2 and Snail regulated by JNK/Notch and Akt/GSK-3 $\beta$ pathways on high glucose-induced E-cadherin repression and migration of hUCB-MSCs. Furthermore, our skin wound healing results showed that silencing EZH2 or Snail suppressed the wound healing effect of hUCB-MSCs and decreased the migration of transplanted cells into the wound sites. These data indicate that both EZH2 and Snail are critical factors in determining the therapeutic efficacy of high glucose-pretreated hUCB-MSCs. However, further investigations into the role of high glucose-induced epigenetic regulation of E-cadherin in other physiological functions of hUCB-MSC are needed to understand the therapeutic potential of high glucose for stem cell therapy.

\section{Conclusion}

In summary, we have shown that high glucose-induced E-cadherin repression increases migration through the expressions of EZH2 and Snail. High glucose specifically induces the recruitment of PRC2 to the E-cadherin promoter, where high glucose triggers ROS production to promote either the activation of JNK-mediated cleaved Notch or PI3K/Akt signaling pathways (Fig. 6). Moreover, high glucose pretreatment improved the migratory ability of the transplanted hUCB-MSCs to the wound site, which facilitates tissue regeneration. Therefore, we strongly suggest that pre-activation by high glucose promotes the therapeutic capability of hUCB-MSCs for clinical skin wound treatment models. 


\section{Cellular Physiology Cell Physiol Biochem 2018;46:1749-1767 \begin{tabular}{ll|l} 
and Biochemistry Published onIIne: April 30, 2018 & $\begin{array}{l}\text { (C) } 2018 \text { The Author(s). Published by S. Karger AG, Basel } \\
\text { www.karger.com/cpb }\end{array}$
\end{tabular}}

Oh et al.: High Glucose Mediates hUCB-MSC Migration

\section{Acknowledgements}

This work was supported by National R\&D Program through the National Research Foundation of Korea (NRF) funded by the Ministry of Science, ICT \& Future Planning [NRF2013M3A9B4076520]; [NRF-2017R1A2B 2008661] and BK21 PLUS Program for Creative Veterinary Science Research.

\section{Disclosure Statement} article.

The authors declare that they have no conflicts of interest with the contents of this

\section{References}

1 Saki N, Jalalifar MA, Soleimani M, Hajizamani S, Rahim F: Adverse effect of high glucose concentration on stem cell therapy. Int J Hematol Oncol Stem Cell Res 2013;7:34-40.

2 Madonna R, Gorbe A, Ferdinandy P, De Caterina R: Glucose metabolism, hyperosmotic stress, and reprogramming of somatic cells. Mol Biotechnol 2013;55:169-178.

3 Ito K, Suda T: Metabolic requirements for the maintenance of self-renewing stem cells. Nat Rev Mol Cell Biol 2014;15:243-256.

-4 Chang TC, Hsu MF, Wu KK: High glucose induces bone marrow-derived mesenchymal stem cell senescence by upregulating autophagy. PLoS One 2015;10:e0126537.

5 McClelland Descalzo DL, Satoorian TS, Walker LM, Sparks NR, Pulyanina PY, Zur Nieden NI: Glucoseinduced oxidative stress reduces proliferation in embryonic stem cells via FOXO3a/ $\beta$-Catenin-dependent transcription of p21(cip1). Stem Cell Reports 2016;7:55-68.

-6 Li YM, Schilling T, Benisch P, Zeck S, Meissner-Weigl J, Schneider D, Limbert C, Seufert J, Kassem M, Schutze N, Jakob F, Ebert R: Effects of high glucose on mesenchymal stem cell proliferation and differentiation. Biochem Biophys Res Commun 2007;363:209-215.

7 Dhanasekaran M, Indumathi S, Rajkumar JS, Sudarsanam D: Effect of high glucose on extensive culturing of mesenchymal stem cells derived from subcutaneous fat, omentum fat and bone marrow. Cell Biochem Funct 2013;31:20-29.

-8 Sen S, Domingues CC, Rouphael C, Chou C, Kim C, Yadava N: Genetic modification of human mesenchymal stem cells helps to reduce adiposity and improve glucose tolerance in an obese diabetic mouse model. Stem Cell Res Ther 2015;6:242.

-9 Horwitz EM, Prockop DJ, Fitzpatrick LA, Koo WW, Gordon PL, Neel M, Sussman M, Orchard P, Marx JC, Pyeritz RE, Brenner MK: Transplantability and therapeutic effects of bone marrow-derived mesenchymal cells in children with osteogenesis imperfecta. Nat Med 1999;5:309-313.

-10 Sohni A, Verfaillie CM: Mesenchymal stem cells migration homing and tracking. Stem Cells Int 2013;2013:130763.

11 De Becker A, Riet IV: Homing and migration of mesenchymal stromal cells: How to improve the efficacy of cell therapy? World J Stem Cells 2016;8:73-87.

12 Zhang W, Schmull S, Du M, Liu J, Lu Z, Zhu H, Xue S, Lian F: Estrogen receptor $\alpha$ and $\beta$ in mouse: adiposederived stem cell proliferation, migration, and brown adipogenesis in vitro. Cell Physiol Biochem 2016;38:2285-2299.

13 Liu L, Yu Q, Hu K, Wang B, Zhang Y, Xu Y, Fu S, Yu X, Huang H: Electro-acupuncture promotes endogenous multipotential mesenchymal stem cell mobilization into the peripheral blood. Cell Physiol Biochem 2016;38:1605-1617.

14 Takatani-Nakase T, Matsui C, Maeda S, Kawahara S, Takahashi K: High glucose level promotes migration behavior of breast cancer cells through zinc and its transporters. PLoS One 2014;9:90136. 


\section{Cellular Physiology Cell Physiol Biochem 2018;46:1749-1767 \begin{tabular}{ll|l} 
and Biochemistry Published onlıne: April 30, 2018 & $\begin{array}{l}\text { C } 2018 \text { The Author(s). Published by S. Karger AG, Basel } \\
\text { www.karger.com/cpb }\end{array}$ \\
\hline
\end{tabular}}

Oh et al.: High Glucose Mediates hUCB-MSC Migration

15 Panchatcharam M, Miriyala S, Yang F, Leitges M, Chrzanowska-Wodnicka M, Quilliam LA, Anaya P, Morris AJ, Smyth SS: Enhanced proliferation and migration of vascular smooth muscle cells in response to vascular injury under hyperglycemic conditions is controlled by $\beta 3$ integrin signaling. Int J Biochem Cell Biol 2010;42:965-974.

16 Huang Q Sheibani N: High glucose promotes retinal endothelial cell migration through activation of Src, PI3K/Akt1/eNOS, and ERKs. Am J Physiol Cell Physiol 2008;295:1647-1657.

17 Vogelmann R, Nguyen-Tat MD, Giehl K, Adler G, Wedlich D, Menke A: TGFß-induced downregulation of E-cadherin-based cell-cell adhesion depends on PI3-kinase and PTEN. J Cell Sci 2005;118:4901-4912.

18 Han T, Jiao F, Hu H, Yuan C, Wang L, Jin ZL, Song WF, Wang LW: EZH2 promotes cell migration and invasion but not alters cell proliferation by suppressing E-cadherin, partly through association with MALAT-1 in pancreatic cancer. Oncotarget 2016; 7:11194-11207.

19 Palecek SP, Huttenlocher A, Horwitz AF, Lauffenburger DA: Physical and biochemical regulation of integrin release during rear detachment of migrating cells. J Cell Sci 1998;111:929-940.

20 Webb DJ, Parsons JT, Horwitz AF: Adhesion assembly, disassembly and turnover in migrating cells - over and over and over again. Nat Cell Biol 2002;4:97-100.

21 Kirfel G, Rigort A, Borm B, Herzog V: Cell migration: mechanisms of rear detachment and the formation of migration tracks. Eur J Cell Biol 2004;83:717-724.

22 Takeichi M, Ozaki HS, Tokunaga K, Okada TS: Experimental manipulation of cell surface to affect cellular recognition mechanisms. Dev Biol 1979;70:195-205.

23 Zhu X, Li Y, Zhou R, Wang N, Kang S: Knockdown of E-cadherin expression of endometrial epithelial cells may activate Wnt/ $\beta$-catenin pathway in vitro. Arch Gynecol Obstet 2018;297:117-123.

$\checkmark 24$ Hyafil F, Babinet C, Jacob F: Cell-cell interactions in early embryogenesis: a molecular approach to the role of calcium. Cell 1981;26:447-454.

25 Gumbiner BM: Regulation of cadherin-mediated adhesion in morphogenesis. Nat Rev Mol Cell Biol 2005;6:622-634.

26 Takeichi M: Cadherin cell adhesion receptors as a morphogenetic regulator. Science 1991;251:1451-1455.

-27 Niewiadomska P, Godt D, Tepass U: DE-Cadherin is required for intercellular motility during Drosophila oogenesis. J Cell Biol 1999;144:533-547.

28 Theveneau E, Mayor R: Cadherins in collective cell migration of mesenchymal cells. Curr Opin Cell Biol 2012;24:677-684.

29 Cai D, Chen SC, Prasad M, He L, Wang X, Choesmel-Cadamuro V, Sawyer JK, Danuser G, Montell DJ: Mechanical feedback through E-cadherin promotes direction sensing during collective cell migration. Cell 2014;157:1146-1159.

30 Marambaud P, Shioi J, Serban G, Georgakopoulos A, Sarner S, Nagy V, Baki L, Wen P, Efthimiopoulos S, Shao Z, Wisniewski T, Robakis NK: A presenilin-1/ $\gamma$-secretase cleavage releases the E-cadherin intracellular domain and regulates disassembly of adherens junctions. EMBO J 2002;21:1948-1956.

-31 Pittenger MF, Mackay AM, Beck SC, Jaiswal RK, Douglas R, Mosca JD, Moorman MA, Simonetti DW, Craig S, Marshak DR: Multilineage potential of adult human mesenchymal stem cells. Science 1999;284:143-147.

32 Barry FP, Murphy JM: Mesenchymal stem cells: clinical applications and biological characterization. Int J Biochem Cell Biol 2004;36:568-584.

-33 Lee SS, Lee SJ, Lee SH, Ryu JM, Lim HS, Kim JS, Song EJ, Jung YH, Lee HJ, Kim CH, Han HJ: Netrin-1-induced stem cell bioactivity contributes to the regeneration of injured tissues via the lipid raft-dependent integrin

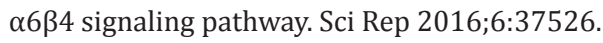

-34 Ryu JM, Han HJ: Autotaxin-LPA axis regulates hMSC migration by adherent junction disruption and cytoskeletal rearrangement via LPAR1/3-dependent PKC/GSK3 $\beta / \beta$-catenin and PKC/Rho GTPase pathways. Stem Cells 2015;33:819-832.

35 Yang SE, Ha CW, Jung M, Jin HJ, Lee M, Song H, Choi S, Oh W, Yang YS: Mesenchymal stem/progenitor cells developed in cultures from UC blood. Cytotherapy 2004;6:476-486.

-36 Jung YH, Lee SJ, Oh SY, Lee HJ, Ryu JM, Han HJ: Oleic acid enhances the motility of umbilical cord blood derived mesenchymal stem cells through EphB2-dependent F-actin formation. Biochim Biophys Acta 2015;1853:1905-1917.

-37 Chang YS, Choi SJ, Ahn SY, Sung DK, Sung SI, Yoo HS, Oh WI, Park WS: Timing of umbilical cord blood derived mesenchymal stem cells transplantation determines therapeutic efficacy in the neonatal hyperoxic lung injury. PLoS One 2013;8:52419. 


\section{Cellular Physiology Cell Physiol Biochem 2018;46:1749-1767 \begin{tabular}{l|l} 
and Biochemistry Published onIIne: April 30, 2018 & $\begin{array}{l}\text { (c) } 2018 \text { The Author(s). Published by S. Karger AG, Basel } \\
\text { www.karger.com/cpb }\end{array}$
\end{tabular}}

38 Wang X, Ge J, Tredget EE, Wu Y: The mouse excisional wound splinting model, including applications for stem cell transplantation. Nat Protoc 2013;8:302-309.

-39 Song EJ, Lee SJ, Lim HS, Kim JS, Jang KK, Choi SH, Han HJ: Vibrio vulnificus VvhA induces autophagy-related cell death through the lipid raft-dependent c-Src/NOX signaling pathway. Sci Rep 2016;6:27080.

-40 Huang Q Sheibani N: High glucose promotes retinal endothelial cell migration through activation of Src, PI3K/Akt1/eNOS, and ERKs. Am J Physiol Cell Physiol 2008;295:C1647-1657.

41 Lee YJ, Han HJ: Troglitazone ameliorates high glucose-induced EMT and dysfunction of SGLTs through PI3K/Akt, GSK-3 $\beta$, Snail1, and $\beta$-catenin in renal proximal tubule cells. Am J Physiol Renal Physiol 2010;298:F1263-1275.

42 Stambolic V, Ruel L, Woodgett JR: Lithium inhibits glycogen synthase kinase-3 activity and mimics wingless signalling in intact cells. Curr Biol 1996;6:1664-1668.

43 Herranz N, Pasini D, Diaz VM, Franci C, Gutierrez A, Dave N, Escriva M, Hernandez-Munoz I, Di Croce L, Helin K, Garcia de Herreros A, Peiro S: Polycomb complex 2 is required for E-cadherin repression by the Snail1 transcription factor. Mol Cell Biol 2008;28:4772-4781.

44 Suzuki N, Svensson K, Eriksson UJ: High glucose concentration inhibits migration of rat cranial neural crest cells in vitro. Diabetologia 1996;39:401-411.

45 Farnoodian M, Halbach C, Slinger C, Pattnaik BR, Sorenson CM, Sheibani N: High glucose promotes the migration of retinal pigment epithelial cells through increased oxidative stress and PEDF expression. Am J Physiol Cell Physiol 2016;311:418-436.

46 Rosova I, Dao M, Capoccia B, Link D, Nolta JA: Hypoxic preconditioning results in increased motility and improved therapeutic potential of human mesenchymal stem cells. Stem Cells 2008;26:2173-2182.

47 Oh SY, Lee SJ, Jung YH, Lee HJ, Han HJ: Arachidonic acid promotes skin wound healing through induction of human MSC migration by MT3-MMP-mediated fibronectin degradation. Cell Death Dis 2015;6:e1750.

-48 Ko SH, Choi GE, Oh JY, Lee HJ, Kim JS, Chae CW, Choi D, Han HJ: Succinate promotes stem cell migration through the GPR91-dependent regulation of DRP1-mediated mitochondrial fission. Sci Rep 2017;7:12582.

49 Chen JS, Wong VW, Gurtner GC: Therapeutic potential of bone marrow-derived mesenchymal stem cells for cutaneous wound healing. Front Immunol 2012;3:192.

-50 Lee SJ, Jung YH, Oh SY, Yong MS, Ryu JM, Han HJ: Netrin-1 induces MMP-12-dependent E-cadherin degradation via the distinct activation of PKC $\alpha$ and FAK/Fyn in promoting mesenchymal stem cell motility. Stem Cells Dev 2014;23:1870-1882.

51 Serrano-Gomez SJ, Maziveyi M, Alahari SK: Regulation of epithelial-mesenchymal transition through epigenetic and post-translational modifications. Mol Cancer 2016;15:18.

52 Di Croce L, Helin K: Transcriptional regulation by Polycomb group proteins. Nat Struct Mol Biol 2013;20:1147-1155.

-53 Ha H, Lee HB: Reactive oxygen species as glucose signaling molecules in mesangial cells cultured under high glucose. Kidney Int Suppl 2000;77:19-25.

54 Schroder K: NADPH oxidases in redox regulation of cell adhesion and migration. Antioxid Redox Signal 2014;20:2043-2058.

55 Chess PR, O'Reilly MA, Sachs F, Finkelstein JN: Reactive oxidant and p42/44 MAP kinase signaling is necessary for mechanical strain-induced proliferation in pulmonary epithelial cells. J Appl Physiol 2005;99:1226-1232.

-56 Lee YS, Kang YS, Lee JS, Nicolova S, Kim JA: Involvement of NADPH oxidase-mediated generation of reactive oxygen species in the apototic cell death by capsaicin in HepG2 human hepatoma cells. Free Radic Res 2004;38:405-412.

57 Sauer H, Wartenberg M, Hescheler J: Reactive oxygen species as intracellular messengers during cell growth and differentiation. Cell Physiol Biochem 2001;11:173-186.

58 Zhang L, Pang S, Deng B, Qian L, Chen J, Zou J, Zheng J, Yang L, Zhang C, Chen X, Liu Z, Le Y: High glucose induces renal mesangial cell proliferation and fibronectin expression through JNK/NF- $\mathrm{B} / \mathrm{NADPH}$ oxidase/ ROS pathway, which is inhibited by resveratrol. Int J Biochem Cell Biol 2012;44:629-638.

59 Shen C, Chen Y, Liu H, Zhang K, Zhang T, Lin A, Jing N: Hydrogen peroxide promotes A $\beta$ production through JNK-dependent activation of $\gamma$-secretase. J Biol Chem 2008;283:17721-17730.

60 Kim SK, Park HJ, Hong HS, Baik EJ, Jung MW, Mook-Jung I: ERK1/2 is an endogenous negative regulator of the $\gamma$-secretase activity. FASEB J 2006;20:157-159. 


\section{Cellular Physiology Cell Physiol Biochem 2018;46:1749-1767

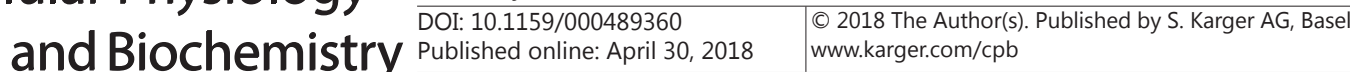

Oh et al.: High Glucose Mediates hUCB-MSC Migration

61 Gonzalez ME, Moore HM, Li X, Toy KA, Huang W, Sabel MS, Kidwell KM, Kleer CG: EZH2 expands breast stem cells through activation of NOTCH1 signaling. Proc Natl Acad Sci U S A 2014;111:3098-3103.

-62 Guo J, Xia N, Yang L, Zhou S, Zhang Q, Qiao Y, Liu Z: GSK-3 $\beta$ and vitamin D receptor are involved in $\beta$-catenin and snail signaling in high glucose-induced epithelial-mesenchymal transition of mouse podocytes. Cell Physiol Biochem 2014;33:1087-1096.

63 Wang H, Fang R, Wang XF, Zhang F, Chen DY, Zhou B, Wang HS, Cai SH, Du J: Stabilization of Snail through AKT/GSK-3 $\beta$ signaling pathway is required for TNF- $\alpha$-induced epithelial-mesenchymal transition in prostate cancer PC3 cells. Eur J Pharmacol 2013;714:48-55.

64 Kim YH, Heo JS, Han HJ: High glucose increase cell cycle regulatory proteins level of mouse embryonic stem cells via PI3-K/Akt and MAPKs signal pathways. J Cell Physiol 2006;209:94-102.

65 Zhang B, Liu N, Shi H, Wu H, Gao Y, He H, Gu B, Liu H: High glucose microenvironments inhibit the proliferation and migration of bone mesenchymal stem cells by activating GSK3 $\beta$. J Bone Miner Metab 2016;34:140-150.

66 Nieto MA: The snail superfamily of zinc-finger transcription factors. Nat Rev Mol Cell Biol 2002;3:155-166.

67 Doble BW, Woodgett JR: Role of glycogen synthase kinase-3 in cell fate and epithelial-mesenchymal transitions. Cells Tissues Organs 2007;185:73-84.

68 Lunyak VV, Rosenfeld MG: Epigenetic regulation of stem cell fate. Hum Mol Genet 2008;17:R28-36.

69 Wang C, Yue Y, Shao B, Qiu Z, Mu J, Tang J, Han X, Xiang T, Ren G: Dickkopf-Related Protein 2 is epigenetically inactivated and suppresses colorectal cancer growth and tumor metastasis by antagonizing Wnt/ $\beta$-Catenin signaling. Cell Physiol Biochem 2017;41:1709-1724.

-70 Simon JA, Kingston RE: Occupying chromatin: Polycomb mechanisms for getting to genomic targets, stopping transcriptional traffic, and staying put. Mol Cell 2013;49:808-824.

71 Tien CL, Jones A, Wang H, Gerigk M, Nozell S, Chang C: Snail2/Slug cooperates with Polycomb repressive complex 2 (PRC2) to regulate neural crest development. Development 2015;142:722-731.

-72 Tong ZT, Cai MY, Wang XG, Kong LL, Mai SJ, Liu YH, Zhang HB, Liao YJ, Zheng F, Zhu W, Liu TH, Bian XW, Guan XY, Lin MC, Zeng MS, Zeng YX, Kung HF, Xie D: EZH2 supports nasopharyngeal carcinoma cell aggressiveness by forming a co-repressor complex with HDAC1/HDAC2 and Snail to inhibit E-cadherin. Oncogene 2012;31:583-594.

73 Peinado H, Ballestar E, Esteller M, Cano A: Snail mediates E-cadherin repression by the recruitment of the Sin3A/histone deacetylase 1 (HDAC1)/HDAC2 complex. Mol Cell Biol 2004;24:306-319.

74 von Burstin J, Eser S, Paul MC, Seidler B, Brandl M, Messer M, von Werder A, Schmidt A, Mages J, Pagel P, Schnieke A, Schmid RM, Schneider G, Saur D: E-cadherin regulates metastasis of pancreatic cancer in vivo and is suppressed by a SNAIL/HDAC1/HDAC2 repressor complex. Gastroenterology 2009;137:361-371, 371 e361-365.

75 Munshi A, Kurland JF, Nishikawa T, Tanaka T, Hobbs ML, Tucker SL, Ismail S, Stevens C, Meyn RE: Histone deacetylase inhibitors radiosensitize human melanoma cells by suppressing DNA repair activity. Clin Cancer Res 2005;11:4912-4922.

-76 Lin Y, Dong C, Zhou BP: Epigenetic regulation of EMT: the Snail story. Curr Pharm Des 2014;20:1698-1705. 